\title{
CARDIAC ALLOGRAFT VASCULOPATHY IN PARTIALLY INBRED MINIATURE SWINE. I. TIME COURSE, PATHOLOGY, AND DEPENDENCE ON IMMUNE MECHANISMS
}

Joren C. Madsen, MD, DPhil

David H. Sachs, MD

John T. Fallon, MD, $\mathrm{PhD}^{*}$

Neil J. Weissman, MD $^{* *}$
To assess the role of the immune system in cardiac allograft vasculopathy in large animals, heterotopic heart transplantation was done between partially inbred miniature swine, animals in which transplantation can be done across defined major histocompatibility barriers in a reproducible fashion. Porcine hearts transplanted into untreated recipients across a class I, class II, or full major histocompatibility mismatch were acutely rejected in 6 to 8 days $(n=4)$. Hearts transplanted into untreated recipients across minor histocompatibility barriers survived for 21 to 44 days $(n=5$ ) and showed no evidence of cardiac allograft vasculopathy. When recipients were treated with a 12-day course of cyclosporine, hearts transplanted across minor histocompatibility barriers survived 42,64 , and 56 days and did not develop vascular lesions. However, hearts transplanted into cyclosporine-treated recipients across a full major histocompatibility disparity survived 20,22 , and 23 days and all three developed biopsyproven vasculopathy. In one animal, the progression of intimal proliferation was followed in vivo by intracoronary ultrasonography. The degree of intimal thickening documented by ultrasonography correlated well with the intimal proliferation found on tissue histologic samples. These results are the first to show that in large animals, an immune response stimulated by donor major histocompatibility antigens is involved in the induction of cardiac allograft vasculopathy. In addition, these studies point out the utility of a large-animal model of cardiac allograft vasculopathy in which transplantation across defined major histocompatibility barriers can be done reproducibly and in which accurate determinations of the progression or regression of coronary vascular lesions in individual animals can be accurately assessed in vivo. (J Thorac Cardiovasc Surg 1996;111:1230-9)
$T_{\text {he }}^{\text {h }}$ he short-term results of heart transplantation have improved dramatically during the past 25 years with survival rates at 1 year increasing from $22 \%$ in $1969^{1}$ to more than $80 \%$ in $1993 .^{2}$ However, the progress made in the detection, prevention, and

From the Cardiac Surgical Unit and Transplantation Biology Research Center, Department of Surgery, Massachusetts General Hospital, Harvard Medical School, Boston, Mass.

Received for publication May 18, 1995; accepted for publication July 26, 1995.

Address for reprints: Joren C. Madsen, MD, DPhil, Department of Surgery, Massachusetts General Hospital, 55 Fruit St., Boston, MA 02114.

*Current address: Division of Pathology, Mount Sinai Medical Center, Cardiovascular Institute, New York, N.Y.

* Current address: Division of Cardiology, Georgetown University Medical Center, Washington, D.C.

Copyright $\mathbb{C} 1996$ by Mosby-Year Book, Inc.

$0022-5223 / 96 \$ 5.00+0 \quad \mathbf{1 2} / \mathbf{1} / \mathbf{6 8 2 3 1}$ treatment of acute rejection has been overshadowed by the poorly understood problem of cardiac allograft vasculopathy (CAV). This disease is manifested by a diffuse and accelerated form of atherosclerosis that often involves entire lengths of coronary arteries. Autopsy findings reveal that virtually all transplant recipients who survive for more than a year demonstrate intimal changes. ${ }^{3}$ Indeed, in many series, CAV is the leading cause of death or graft failure after the first posttransplant year. ${ }^{4}$ Nonetheless, the cause of CAV remains a mystery and at present there is no effective treatment for this disease.

Experimental studies investigating the immunologic basis of CAV have been primarily done in rodent models with the use of whole-organ or arterial allografts. ${ }^{5}$ Although these studies have yielded important information, many of the results from experiments that attemped to elucidate the 
potential immune mediators of CAV have been conflicting. Some studies have implicated antibodies specific for donor antigens in the development of intimal proliferation in rodents, ${ }^{6}$ whereas others have supported the predominance of $\mathbf{T}$ cell-mediated immunity directed against the host ${ }^{7}$ or activated macrophages. ${ }^{8}$ Of course, it is possible that multiple forms of immunity might participate in the pathogenesis of CAV.

To investigate the immunobiologic basis of CAV in large animals, we performed heterotopic heart transplants between partially inbred miniature swine. Miniature swine bring several unique advantages to the study of CAV. Unlike those of rodents, the porcine immune and cardiovascular systems are similar to those of human beings, as is the porcine susceptibility to atherosclerosis. ${ }^{9-11}$ Transplantation across defined major histocompatibility (MHC) barriers can be done reproducibly in these animals, making it possible to study the dependence of CAV on MHC genetics. ${ }^{12}$ Also, the coronary arteries of the transplanted heart are large enough to be imaged with intracoronary ultrasonography (ICUS), making miniswine the only experimental model of CAV in which the effects of treatment can be accurately assessed in vivo.

In this article we describe and validate a largeanimal, preclinical model of CAV with the use of miniature swine, which develop vascular lesions identical to those observed in clinical transplantation. Data are presented that support the hypothesis that the induction of CAV in large animals is mediated by an immune response stimulated by MHC antigen.

\section{Material and methods}

Animals. During the past 25 years, a selective breeding program has been used to develop and maintain miniature swine with defined MHC loci (termed SLA, for swine leukocyte antigens) as a large-animal model for studies of transplantation biology. ${ }^{12}$ At present, swine of three homozygous MHC haplotypes, SLA ${ }^{\mathrm{a}}, \mathrm{SLA}^{\mathrm{c}}$, and SLA ${ }^{\mathrm{d}}$, are maintained (Fig. 1). In addition, swine bearing four intra-MHC recombinant haplotypes have been derived by spontaneous recombination events during the breeding of heterozygotes as part of the breeding program (Fig. 1) ${ }^{13}$ Genotyping has been controlled by strict pedigree breeding and confirmed by microcytotoxicity testing with allospecific antisera.

All animal care and procedures were in compliance with the "Principles of Laboratory Animal Care" formulated by the National Society for Medical Research and the "Guide for the Care and Use of Laboratory Animals" prepared by the Institute of Laboratory Animal Resources

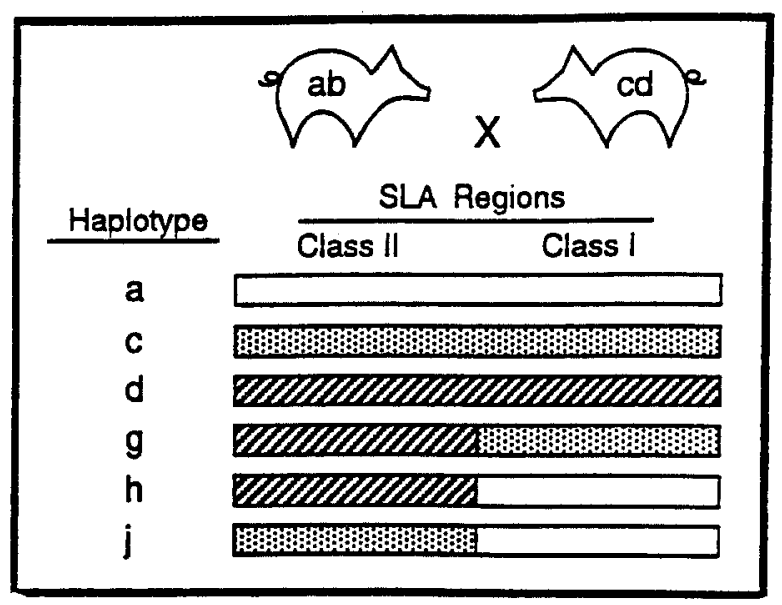

Fig. 1. Origin of available MHC haplotypes of partially inbred miniature swine.

and published by the National Institutes of Health (NIH Publication No. 86-23, revised 1985).

Heterotopic cardiac transplants. Transplant donors and recipients (4 to 6 months old and weighing between 15 and $40 \mathrm{~kg}$ ) were fasted overnight, then sedated with ketamine $(20 \mathrm{mg} / \mathrm{kg}$ ), butorphanol (Torbugesic, $0.2 \mathrm{mg}$ / $\mathrm{kg}$ ), and xylazine ( $2 \mathrm{mg} / \mathrm{kg}$ ) intramuscularly for scrubbing, shaving, and intubation. Anesthesia was maintained with halothane $1 \%, \mathrm{~N}_{2} \mathrm{O} 1 \%$, and $\mathrm{O}_{2}$. The recipient was placed in the left lateral decubitus position and a Hickman catheter was placed in the left external jugular vein for long-term vascular access. A left flank incision was done and, by a retroperitoneal approach, the infrarenal aorta and inferior vena cava were isolated. Next, the donor was systemically heparinized $(3 \mathrm{mg} / \mathrm{kg})$ and the donor heart harvested after cardiac standstill was achieved with cold $\left(4^{\circ} \mathrm{C}\right)$ cardioplegic solution (Plegisol, Abbott Laboratories, North Chicago, Ill.). An atrial septal defect was created in each donor heart and the mitral valve defunctionalized to minimize left ventricular atrophy and intracavitary thrombus formation. ${ }^{14,15}$ The recipient was systemically heparinized $(3 \mathrm{mg} / \mathrm{kg})$ and the donor pulmonary artery was anastomosed end-to-side to a 1 to $2 \mathrm{~cm}$ venotomy in the inferior vena cava with a continuous 6-0 polypropylene suture (Prolene, Ethicon, Inc., Somerville, N.J.). Next, the ascending aorta of the donor heart was anastomosed to the recipient's abdominal aorta in a similar manner. A 2 to $4 \mathrm{~mm}$ cuff of aortic wall was resected around the aortotomy before construction of the anastomosis to avoid stricture formation. Neither cold ischemic times nor warm ischemic times exceeded 45 minutes. In most cases, removal of the aortic crossclamp resulted in spontaneous conversion to a normal sinus rhythm. However, in some cases internal electrical defibrillation (10 to 20 joules) was necessary. Before closure of the abdominal wall, iridium-tipped ventricular electrodes (model 6500 pacing lead, Medtronic Inc., Secaucus, N.J.) were implanted into each ventricle and brought out through the skin for long-term electrocardiographic monitoring. 
Table I. Pathologic grading of heart tissue from biopsy or necropsy samples

\begin{tabular}{ll}
\hline & Grade \\
\hline Histologic evidence of arterial intimal thickening & \\
Normal artery & 0 \\
$<10 \%$ occlusion of lumen by intimal prolifera- & 1 \\
$\quad$ tion or inflammatory cells & 2 \\
$>10 \%$ but $<50 \%$ occlusion of lumen & 3 \\
$>50 \%$ occlusion of lumen & \\
Histologic evidence of interstitial rejection & 0 \\
$\quad$ No rejection & $1 \mathrm{a}$ \\
Focal (perivascular/interstitial) infiltrate without \\
$\quad$ necrosis
\end{tabular}

Heart function was monitored by transabdominal palpation, electrocardiography (EK/5A, Burdick Corp., Milton, Wis.), and echocardiography (Sonos 1500, HewlettPackard, Andover, Mass.). Allograft rejection (heart survival time) was defined by one or more of the following: lack of a ventricular impulse on palpation, an $\mathrm{R}$ wave of less than $3 \mathrm{~mm}$ amplitude on electrocardiography, or lack of ventricular contraction on echocardiography. After allograft rejection, the animal was put to death and the allograft harvested for histologic examination.

On posttransplant days $7,14,21,28$, and 50 percutaneous biopsy samples of the transplanted heart were obtained with a spring-loaded biopsy device (Monopty, Waltham, Mass.) with ultrasonographic guidance. On posttransplant days 8 and 21, animal No. 11531 underwent ICUS to validate its applicability.

Most of the inbred miniature swine herd is seropositive for porcine cytomegalovirus (personal communication, Dr. Jay A. Fishman). Cholesterol levels in the recipients remained consistently low before and after transplantation.

Coronary hemodynamics. Blood pressure was transduced via a 25-gauge needle inserted directly into the proximal left anterior descending artery (LAD) before the first diagonal branch. Blood flow was measured with an ultrasonic flow probe (Transonics Systems, Ithaca, N.Y.) placed circumferentially around the proximal LAD.

Histopathologic examination. Heart tissue from biopsy or necropsy specimens was fixed in $10 \%$ formalin. The graft tissues were embedded in paraffin and then stained with hematoxylin and eosin or Masson's trichrome stain. An effort was made to examine a range of vessels in the transplanted heart, including epicardial and muscular arteries and arterioles. Histologic findings were scored with the use of light microscopy to determine the severity of interstitial rejection, which was based on a modification of the International Society for Heart and Lung Trans-
Table II. Effects of MHC matching on cardiac allograft survival in untreated miniswine*

\begin{tabular}{clcc}
\hline $\begin{array}{c}\text { Recipient } \\
\text { No. }\end{array}$ & $\begin{array}{c}\text { MHC } \\
\text { mismatch }\end{array}$ & $\begin{array}{c}\text { Strain } \\
\text { combination }\end{array}$ & $\begin{array}{c}\text { Survival } \\
\text { (days) }\end{array}$ \\
\hline 830 & Full MHC & $\mathrm{ag} \rightarrow \mathrm{cc}$ & 7 \\
828 & Full MHC & $\mathrm{ag} \rightarrow \mathrm{cc}$ & 8 \\
2513 & Class I & $\mathrm{ad} \rightarrow \mathrm{ag}$ & 8 \\
2511 & Class II & $\mathrm{cc} \rightarrow \mathrm{ag}$ & 6 \\
2499 & None & $\mathrm{cc} \rightarrow \mathrm{cc}$ & 35 \\
2502 & None & $\mathrm{cc} \rightarrow \mathrm{cc}$ & 39 \\
818 & None & $\mathrm{cc} \rightarrow \mathrm{cc}$ & 28 \\
828 & None & $\mathrm{cc} \rightarrow \mathrm{cc}$ & 44 \\
10607 & None & $\mathrm{dd} \rightarrow \mathrm{dd}$ & 21 \\
\hline
\end{tabular}

* All control animals underwent transplantation by Dr. Chris Stone (see Stone and associates ${ }^{29}$ ) except no. 10607.

plantation system, ${ }^{16}$ and the degree of arterial intimal thickening, which was based on the system described by Lurie and colleagues ${ }^{17}$ (Table I). The average grade of intimal thickening of all small, medium, and large arterial vessels was determined and labeled "mean average involvement." 18 All histologic sections were read in a blinded manner.

Immunosuppression. Cyclosporine was generously provided by Sandoz (Hanover, N.J.). Cyclosporine was administered to designated recipients intravenously beginning on the day of operation (postoperative day 0 ) and continuing until posttransplant day 11. Cyclosporine blood levels (fluorescence polarization immunoassay) were maintained between 500 and $1000 \mathrm{ng} / \mathrm{ml}$ by varying the cyclosporine dosage between 10 and $13 \mathrm{mg} / \mathrm{kg}$ per day. This regimen has proved effective in prolonging the survival of SLA class I kidney transplants in miniature swine. ${ }^{19}$

ICUS. The right or left carotid artery was accessed via cutdown under sterile conditions. An $8 \mathrm{~F}$ guiding catheter was inserted into the ostium of the left main coronary artery under fluoroscopic guidance. Coronary angiography was done in orthogonal views with the use of $50 \%$ Hypaque preparation. ICUS imaging was obtained with a $2.9 \mathrm{~F}$ ultrasonography catheter (Cardiovascular Imaging Systems, Sunnyvale, Calif.) with a 30 $\mathrm{MHz}$ transducer rotating at $1800 \mathrm{RPM}$ to produce a 360-degree tomographic image. This catheter has an axial and lateral resolution of $150 \mu \mathrm{m}$ or less. After placement of a 0.014-inch guide wire into the LAD, the ICUS catheter was advanced over the wire under fluoroscopic guidance to a segment of the LAD previously marked with a titanium clip at the time of transplantation.

Imaging was begun as the transducer was withdrawn at $1 \mathrm{~mm} / \mathrm{sec}$ with use of a motorized pullback device and terminated when the aorto-ostial junction of the LAD was reached. Use of a motorized pullback allowed proper alignment of images proximal to the titanium marker so that images from the same location within the artery could be accurately compared at different times. A motorized pullback also allowed three-dimensional reconstruction of the tomographic images by a commercially available pro- 
Table III. Cardiac allograft survival and evolution of lesions in cyclosporine-treated* miniswine bearing $M H C$ matched or MHC-mismatched hearts

\begin{tabular}{|c|c|c|c|c|c|c|c|c|}
\hline \multirow{2}{*}{$\begin{array}{c}\text { MHC } \\
\text { mismatch }\end{array}$} & \multirow{2}{*}{$\begin{array}{c}\text { Animal } \\
\text { No. }\end{array}$} & \multirow{2}{*}{$\begin{array}{c}\text { Strain } \\
\text { combination }\end{array}$} & & \multicolumn{4}{|c|}{ Heart histologic findings } & \multirow{2}{*}{$\begin{array}{l}\text { Survival } \\
\text { (days) }\end{array}$} \\
\hline & & & & Week 1 & Week 2 & Week 3 & Week $\geq 6$ & \\
\hline \multirow[t]{6}{*}{ None } & \multirow[t]{2}{*}{10686} & \multirow[t]{2}{*}{$\mathrm{dd} \rightarrow \mathrm{dd}$} & Vascular: & 0 & 0 & 0 & 0 & \multirow[t]{2}{*}{$56 \dagger$} \\
\hline & & & Interstitial: & 2 & $3 \mathrm{a}$ & $3 a$ & $3 a$ & \\
\hline & \multirow[t]{2}{*}{11252} & \multirow[t]{2}{*}{$\mathrm{dd} \rightarrow \mathrm{dd}$} & Vascular: & 0 & 0 & 0 & 0 & \multirow[t]{2}{*}{42} \\
\hline & & & Interstitial: & $1 \mathrm{a}$ & $1 \mathrm{a}$ & $3 b$ & $3 b$ & \\
\hline & \multirow[t]{2}{*}{11588} & \multirow[t]{2}{*}{$\mathrm{gg} \rightarrow \mathrm{gg}$} & Vascular: & 0 & 0 & 0 & 0 & \multirow[t]{2}{*}{64} \\
\hline & & & Interstitial: & $3 a$ & 1a & $1 b$ & $3 b$ & \\
\hline \multirow{6}{*}{ Full } & \multirow[t]{2}{*}{11531} & \multirow[t]{2}{*}{$\mathrm{cc} \rightarrow \mathrm{dd}$} & Vascular: & 0 & 0 & 3 & & \multirow[t]{2}{*}{23} \\
\hline & & & Interstitial: & $1 b$ & $1 b$ & 4 & & \\
\hline & \multirow[t]{2}{*}{11597} & \multirow[t]{2}{*}{$\mathrm{cc} \rightarrow \mathrm{dd}$} & Vascular: & 0 & 0 & 3 & & \multirow[t]{2}{*}{22} \\
\hline & & & Interstitial: & $1 b$ & $1 b$ & $3 b$ & & \\
\hline & \multirow[t]{2}{*}{10598} & \multirow[t]{2}{*}{$\mathrm{cc} \rightarrow \mathrm{dd}$} & Vascular: & 0 & 0 & 2 & & \multirow[t]{2}{*}{20} \\
\hline & & & Interstitial: & $3 a$ & $3 b$ & $3 b$ & & \\
\hline
\end{tabular}

${ }^{*}$ Cyclosporine 10 to $13 \mathrm{mg} / \mathrm{kg}$ on days 0 through 11 .

† Stenotic aortic anastomosis noted at necropsy.

gram (INDEC System, Capitola, Calif.). All images were recorded on $1 / 2$-inch VHS videotape for further analysis. Measurements were made from images at four discrete locations in the LAD or left main coronary artery. The following dimensions were measured at end-systole: minimal luminal diameter, luminal area, arterial area (defined as the area enclosed by the media-adventitial border), maximal intimal thickness for each quadrant, and plaque area (defined as arterial area minus luminal area). Intimal changes were classified as minimal, mild, moderate, and severe by the classification of St. Goar and associates. ${ }^{20}$

\section{Results}

Cardiac allograft survival in untreated recipients. Hearts transplanted across a full MHC mismatch underwent severe, acute rejection with survival times of 7 and 8 days (Table II). Similarly, hearts transplanted across a single-haplotype class I disparity and a two-haplotype class II disparity were acutely rejected in 8 and 6 days, respectively. Matching for the SLA, on the other hand, led to prolonged survival (mean survival, 33.4 days), with one graft surviving 44 days. None of the SLA-matched hearts went on to long-term survival, most likely because of minor histocompatibility antigen disparities. Histologic examination of these hearts at necropsy revealed no evidence of intimal thickening (personal communication, Dr. Chris Stone). These results demonstrated that both major and minor histocompatibility antigens present strong barriers to heart transplantation in the pig and that immunosuppressive therapy would be necessary to prolong graft survival and permit the development of vascular lesions.
Cardiac allograft survival and development of CAV in cyclosporine-treated recipients. Cyclosporine was chosen for immunosuppression because of its clinical relevance and because a cyclosporine dose-response relationship had already been established in miniswine for kidney transplantation. ${ }^{19}$

First, three SLA-matched hearts were transplanted into recipients treated with a 12-day course of cyclosporine (10 to $13 \mathrm{mg} / \mathrm{kg}$ ). Allograft rejection was only minimally delayed as compared with that in MHC-matched grafts transplanted into untreated recipients (compare Tables II and III). Histologic examination of biopsy and necropsy specimens from these cyclosporine- treated, MHC-matched hearts revealed no intimal thickening in either large or small coronary arteries (Table III).

In contrast, when hearts were transplanted into cyclosporine-treated recipients across a full MHC mismatch, dramatic proliferation of the coronary artery intima was observed in each case even though graft survival times were shorter (20 to 23 days) (Table III). Early lesions exhibited proliferation of spindle cells and matrix in the intima of arteries and arterioles, which resulted in a marked thickening of this layer as compared with findings in normal hearts (Fig. 2, compare $A$ and $B$ ). Later lesions demonstrated deposition of lipid and progressive intimal fibrosis, which in many cases occluded the lumens of both large (Fig. 2, C) and small (Fig. 2, D) arteries. The frequency with which the coronary arteries in tissue sections from cyclosporine-treated, MHCmismatched hearts demonstrated intimal thickening was $70 \%$ to $95 \%$. 

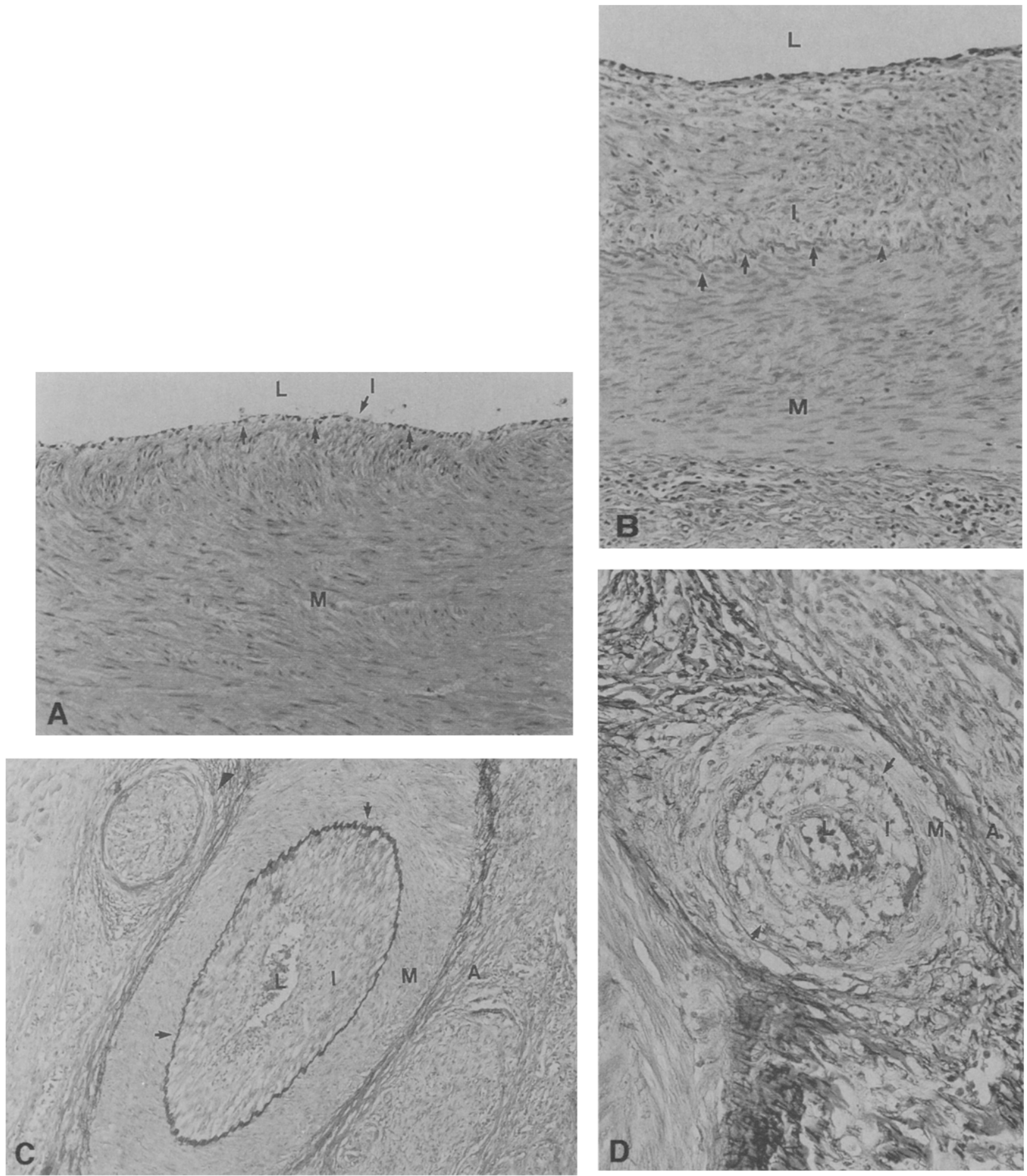

Fig. 2. Photomicrographs of coronary arteries. A, Normal heart stained with hematoxylin and eosin stain (original magnification $\times 400$ ); B, heart No. 11531 stained with hematoxylin and eosin (original magnification $\times 400$ ); C, heart No. 11597 stained with trichrome elastic stain (original magnification $\times 400$ ); $\mathbf{D}$, heart No. 10598 stained with trichrome stain (original magnification $\times 600$. Arrows indicate internal elastic lamina. $L$, Lumen; $I$, intima; $M$, media; $A$, adventitia. 


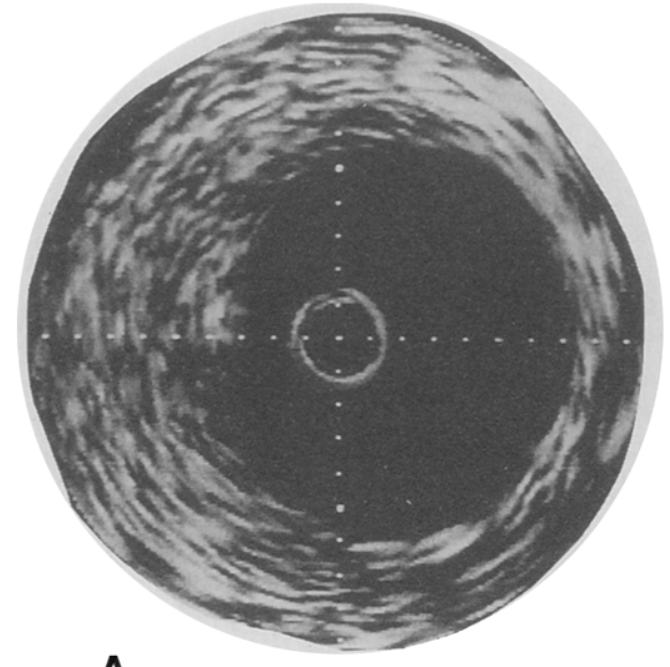

A

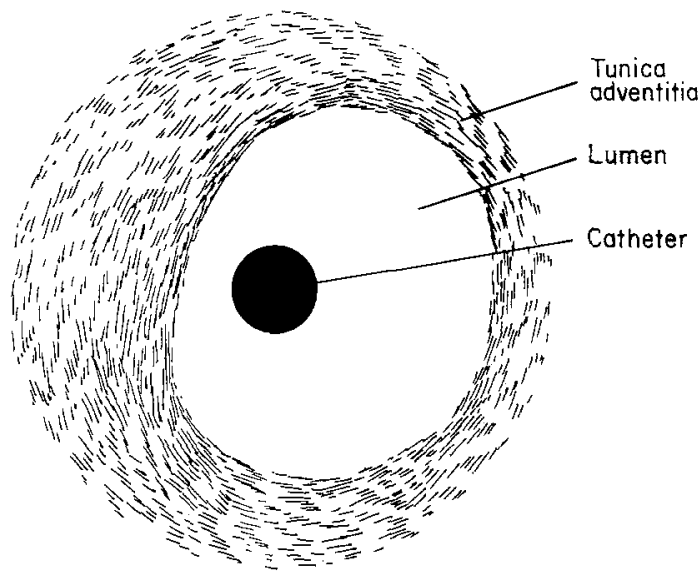

C
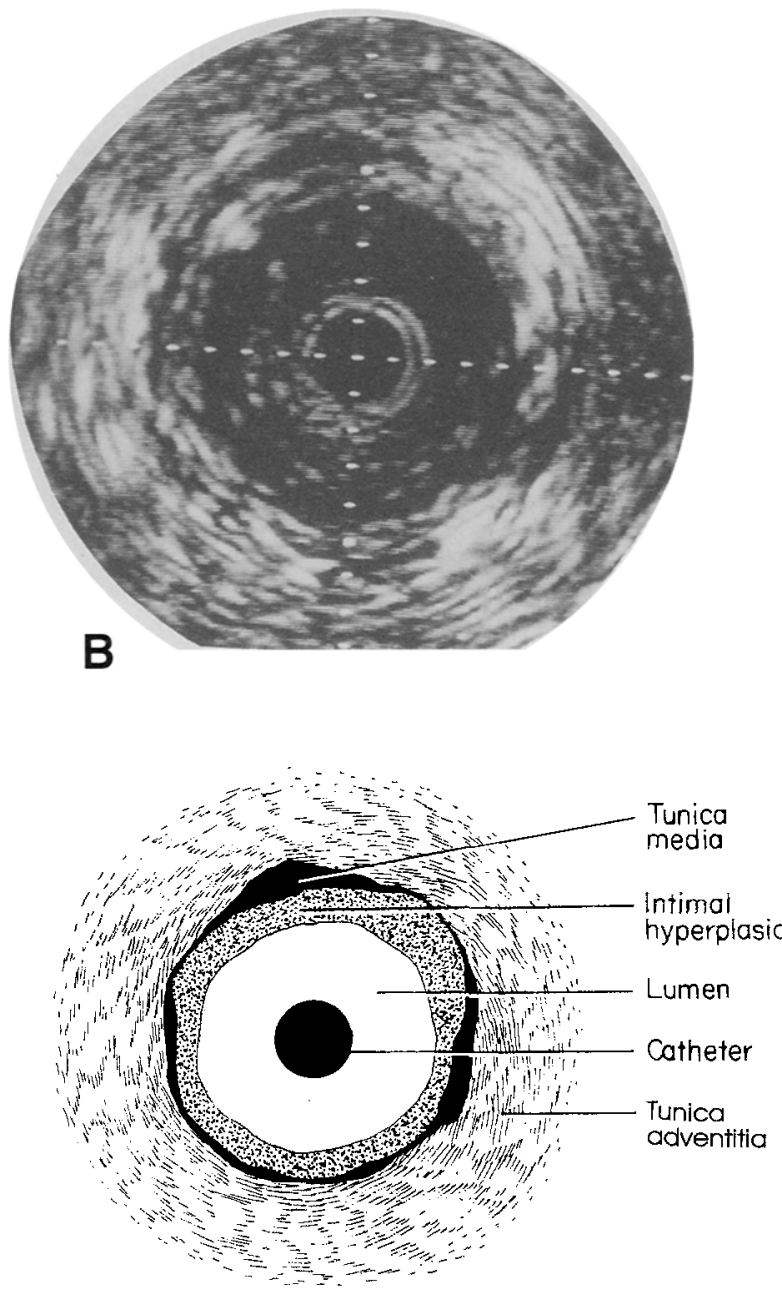

D

Fig 3. ICUS and histologic section of LAD of allograft No. 11531 at posttransplant day 8 (A) and 21 (B). Black central circle is ultrasonographic catheter surrounded by lumen. Graphic representation of ultrasonographic image is beneath actual ultrasonogram (C and D). E, Hematoxylin and eosin-stained section of normal LAD; F, section through area in region of LAD from No. 11531 that corresponded with area imaged by ICUS (original magnification $\times 400$ ).

Imaging with ICUS. ICUS was done in the LAD of recipient No. 11531 on posttransplant days 8 and 21 (Fig. 3). On posttransplant day 8 , no intimal thickening was observed (Fig. 3, $A$ and $C$ ). The thickness of the intima and media was essentially at the resolution of the ultrasonographic catheter (150 $\mu \mathrm{g}$ ) and therefore not visualized. However, by posttransplant day 21, repeat ICUS in a similar location revealed the development of intimal hyperplasia in more than half the circumference of the vessel wall (Fig. 3, $B$ and $D$ ). The increase in intimal thickness measured approximately $0.5 \mathrm{~mm}$, which represents a severe change according to the classification of St. Goar and associates. ${ }^{20}$ After necropsy, photomicrographs were obtained of the LAD from recipient No. 11531 in the same region imaged by ICUS. A similar degree of eccentric intimal thickening was observed (Fig. 3, F). By way of comparison, Fig. 3, E, represents a section of normal $\mathrm{LAD}$ from a naive pig. The slight differences in the overall thickness of the intima and media in the ICUS images as compared with that in the histologic sections were 

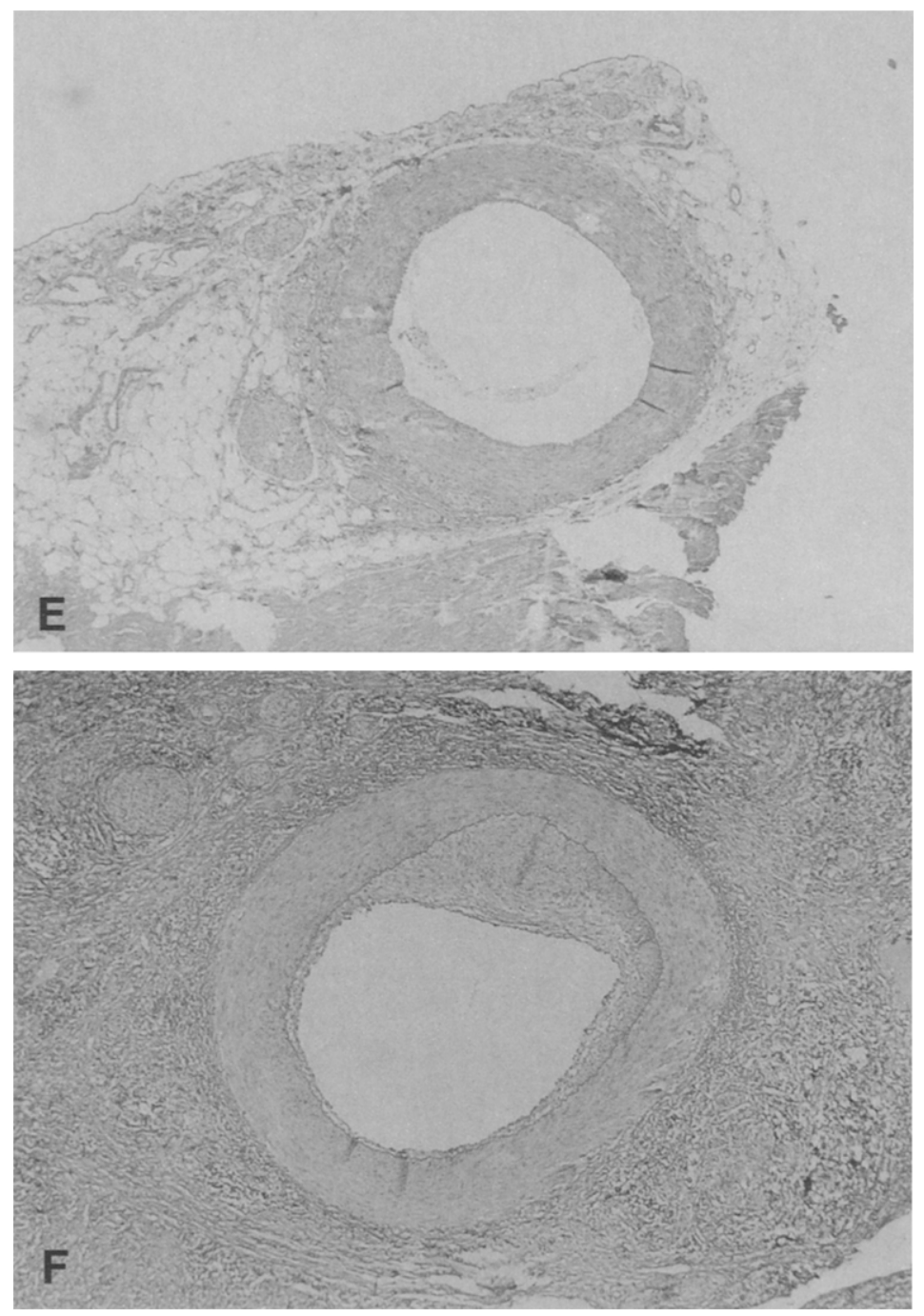

Fig. 3, Cont'd.

probably related to differences in the location of ICUS imaging versus tissue sectioning.

Characteristics of coronary artery blood flow in the native and heterotopically transplanted heart. Coronary artery hemodynamics in native miniswine hearts were compared with coronary flow characteristics in heterotopically transplanted hearts. Table IV depicts the mean blood pressure and blood flow in the LAD of the hearts from donors No. 11043 and 11613 in the native position (before donor cardiectomy) and in the heterotopic position 5 minutes after the aortic crossclamp was removed. The results show that heart rate, mean aortic blood pressure, mean LAD blood pressure, and mean LAD flow all increased proportionately in the heterotopic heart after transplantation (Table IV). These hemody- namic changes were probably related to postischemic hyperemia in the vascular bed of the transplanted heart and the higher systemic blood pressure in the recipient.

\section{Discussion}

This study demonstrated the feasibility and advantages of studying CAV in partially inbred miniature swine. In cyclosporine-treated miniswine, obstructive coronary lesions developed in hearts transplanted across a full MHC barrier but not in cardiac allografts matched at the MHC. The florid vascular lesions, as well as the deposition of lipid, that developed within 4 weeks of transplantation in the coronary arteries of MHCmismatched hearts appeared indistinguishable 
Table IV. Mean blood pressure and flow in LAD of pig No. 11043 and pig No. 11613 before and after transplantation

\begin{tabular}{lcc}
\hline & $\begin{array}{c}\text { Orthotopic } \\
\text { position }\end{array}$ & $\begin{array}{c}\text { Heterotopic } \\
\text { position }\end{array}$ \\
\hline Heart rate (beats/min) & $56 / 42$ & $95 / 86$ \\
Ascending aortic pressure $(\mathrm{mm} \mathrm{Hg})$ & $48 / 55$ & $66 / 71$ \\
LAD pressure $(\mathrm{mm} \mathrm{Hg})$ & $34 / 44$ & $56 / 61$ \\
LAD flow $(\mathrm{ml} / \mathrm{min})$ & $40 / 37$ & $53 / 52$ \\
\hline
\end{tabular}

from atherosclerotic lesions observed in longterm human cardiac grafts. Although results from rodent experiments have led to the view, now rather widely held, that immune phenomena underlie CAV, these findings are the first that indicate that MHC histoincompatibility between donor and recipient is important in the development of CAV in large animals.

The distinction between large animals (including human beings) and small animals is important because significant differences exist between the immune systems and cardiovascular systems of these two groups and in their susceptibility to atherosclerosis. ${ }^{9}$ For instance, it has been demonstrated that rodents do not constitutively express MHC class II antigens on their vascular endothelium, whereas large animals and human beings do. ${ }^{21,22}$ Given the crucial role that class II antigens play in allograft rejection, ${ }^{23}$ these interspecies differences may be important in both early and late alloresponses. ${ }^{24}$ In terms of atherosclerosis, there is evidence that the vigor of an atherogenic response after endothelial injury varies greatly, not only between small animal species, ${ }^{10}$ but even between different strains within the same rodent species. ${ }^{14}$ Moreover, rat coronary arteries have no vasa vasorum, a much thinner intimal layer, and a lower elastin content than human or porcine vessels. ${ }^{25}$

Obviously, the availability of inbred and transgenic rodents, specifically mice, constitutes an important resource for genetic and "knock-out" experiments. However, the vascular lesions that develop in murine coronary arteries differ from those observed in the human being and pig with respect to the lack of lipid deposition in the intimal layer of the vessel wall. ${ }^{5,18}$ Also, nonvascularized arterial transplants, used in some of these experiments, ${ }^{26}$ elicit a different alloresponse than that generated by a vascularized organ allograft. ${ }^{5,27}$ Finally, the interpretation of immune events that take place in rodent models of CAV has been based primarily
Table V. Comparison of rodent and pig models of $C A V$

\begin{tabular}{lccc}
\hline & Mouse & Rat & Pig \\
\hline 1. Defined genetics & ++ & + & + \\
2. Vascular class II expression* & - & $+1-$ & ++ \\
3. Intimal lipid deposition* & $-\dagger$ & - & + \\
4. Nontransplant atherosclerosis* & $-\dagger$ & - & + \\
5. MAbs/DNA probes & ++ & ++ & ++ \\
6. Transgenic animals & + & - & - \\
7. Serial lymphohemopoietic sampling & - & - & + \\
8. Serial biopsies & - & - & + \\
9. In vivo ICUS imaging & - & - & + \\
10. Assessment of coronary hemodynamics & - & - & + \\
11. PET/MRI scanning & - & $+/-$ & + \\
12. Orthotopic transplantation & - & - & +
\end{tabular}

$M A b s$, Monoclonal antibodies; $D N A$, deoxyribonucleic acid; $P E T$, positron emission tomography; $M R I$, magnetic resonance imaging.

*Present in human beings.

$\dagger$ Present in the ApoE knock-out strain. ${ }^{5}$

on the histologic and morphologic findings of graft tissue samples instead of on serial in vitro testing of specific immune effector functions or on in vivo assessment of the progression of intimal thickening.

Because they are large animals, miniature swine are uniquely suited to the study of the immunobiology of CAV (Table V). The porcine MHC has been well-characterized, making it possible to transplant hearts across defined MHC barriers reproducibly. ${ }^{12}$ In addition, various MHC mismatches can be tested with use of a single recipient strain, thus minimizing strain-specific variations in atherogenesis and immune responsiveness (Ir gene effects). Unlike that in rodents, porcine coronary endothelium constitutively expresses class II antigens, similar to this expression in human beings (J. C. M., manuscript submitted). Swine resemble human beings in their cardiovascular physiologic makeup ${ }^{9}$ and in their susceptibility to nontransplant atherosclerosis. ${ }^{11}$ The porcine lymphohematopoietic system allows multiple samplings so that longitudinal analyses of immune effector functions can be done in individual animals with the use of swine-specific monoclonal antibodies and cytokine probes. Similarly, the porcine heart is large enough to allow repeated biopies, orthotopic transplantation, and serial imaging with ICUS. Miniature swine provide the only experimental model of CAV in which the effects of treatment can be accurately assessed in vivo.

The difference in arterial obstructive lesions between MHC-matched and MHC-mismatched grafts 
in our model supports the hypothesis that a persistent, low-grade immunologic injury to coronary artery walls induces the coronary endothelium to respond with a similar inflammatory-fibroproliferative reaction to that observed in nontransplant atherosclerosis. In addition, the observation that both MHC-matched and MHC-mismatched hearts underwent interstitial rejection suggests that although the immune mechanisms responsible for initiating CAV were MHC driven, they may well have been different from the mechanisms that stimulated interstitial rejection. The observation of the former lesion clinically in association with chronic graft loss and that of the latter with acute graft loss further suggests that the afferent mechanisms that mediate acute and chronic rejection may differ. Of note, the possibility that porcine cytomegalovirus contributed to the development of vascular lesions in these studies has not been ruled out and awaits the determination of donor and recipient porcine cytomegalovirus status for each transplant.

Miniature swine will allow us to dissect further the effects of MHC class I versus class II antigen disparities on the induction of CAV and to study the effects of therapy in vivo. Preliminary data in this large-animal system suggest that, unlike conditions in some rodent models, ${ }^{28} \mathrm{MHC}$ class I antigen disparities play an important role in the development of vascular lesions (J. C. M., manuscript submitted). We plan to evaluate whether induction of tolerance to donor class I antigens ${ }^{19}$ can prevent cardiac allograft vasculopathy in this model.

We wish to thank Drs. Paul S. Russell, Robert B. Colvin, and Tomasz Sablinski for their critical review of this manuscript.

\section{REFERENCES}

1. Jamieson SW, Oyer PE, Baldwin JC, Billingham ME, Stinson $\mathrm{EB}$, Shumway NE. Heart transplantation for end-stage ischemic heart disease: the Stanford experience. Heart Transplant 1984;3:224-7.

2. U.S. Department of Health and Human Services. 1994 report of center specific graft and patient survival rates. 1st ed. Bethesda, Maryland: U.S. Department of Health and Human Services, 1995.

3. Uys CJ, Rose AG. Pathologic findings in long-term cardiac transplants. Arch Pathol Lab Med 1984;108:112-6.

4. Billingham ME. Graft coronary disease: the lesions and the patients. Transplant Proc 1989;21:3665-6.

5. Colvin RB, Chase CM, Winn HJ, Russell PS. Chronic allograft arteriopathy: insights from experimental models. Transplant Sci. In press.

6. Russell PS, Chase CM, Winn HJ, Colvin RB. Coronary atherosclerosis in transplanted mouse hearts: II-importance of humoral immunity. J Immunol 1994;152:5135-41.

7. Libby $\mathrm{P}$, Tanaka $\mathrm{H}$. The pathogenesis of coronary arteriosclerosis ("chronic rejection") in transplanted hearts. Clin Transplant 1994;8:313-8.

8. Karnovsky MJ, Russell ME, Hancock WW, Sayegh MH, Adams DH. Chronic rejection in experimental cardiac transplantation in a rat model. Clin Transplant 1994;8:30812.

9. Kirkman RL. Of swine and men: organ physiology in different species. In: Hardy MA, ed. Xenograft 25. 1st ed. Amsterdam: Elsevier, 1989:125-39.

10. Muller D, Ellis S, Topol E. Experimental models of coronary restenosis. J Am Coll Cardiol 1992;19:418-32.

11. Fuster V, Badimon L, Badimon JJ, Ip JH, Chesebro JH. The porcine model for the understanding of thrombogenesis and atherogenesis. Mayo Clin Proc 1991;66:818-31.

12. Sachs DH, Leight G, Cone J, Schwartz S, Stuart L, Rosenberg $S$. Transplantation in miniature swine: $I$ - fixation of the major histocompatibility complex. Transplantation 1976;22: $559-67$.

13. Pennington LR, Lunney JK, Sachs DH. Transplantation in miniature swine: VIII-recombination within the major histocompatibility complex of miniature swine. Transplantation 1981;31:66-75.

14. Paigen B, Morrow A, Brandon C, Mitchell D, Holmes P. Variations in susceptibility to atherosclerosis among inbred strains of mice. Atherosclerosis 1985;57:65-73.

15. Steinbrüchel DA, Nielsen B, Salomon S, Kemp E. A new model for heterotopic heart transplantation in rodents: graft atrial septectomy. Transplant Proc 1994;26:1298-9.

16. Billingham ME. Cardiac transplantation arteriosclerosis. Transplant Proc 1987;19:19-25.

17. Lurie KG, Billingham ME, Jamieson SW, Harrison DC, Reitz BA. Pathogenesis and prevention of graft arteriosclerosis in an experimental heart transplant model. Transplantation 1981;31:41-7.

18. Russell PS, Chase CM, Winn HJ, Colvin RB. Coronary atherosclerosis in transplanted mouse hearts: I-- time course and immunogenetic and immunopathological considerations. Am J Pathol 1994;144:260-74.

19. Rosengard BR, Ojikutu CA, Guzzetta PC, et al. Induction of specific tolerance to class I disparate renal allografts in miniature swine with cyclosporine. Transplantation 1992;54: 490-7.

20. St. Goar FG, Pinto FJ, Alderman EL, et al. Intracoronary ultrasound in cardiac transplant recipients: in vivo evidence of "angiographically silent" intimal thickening. Circulation 1992;85:979-87.

21. Pescovitz MD, Sach DH, Lunney JK, Hsu SM. Localization of class II MHC antigen on porcine renal vascular endothelium. Transplantation 1984;37:627-30.

22. Daar AS, Fuggle SV, Fabre JW, Ting A, Morris PJ. The detailed distribution of MHC class II antigens in normal human organs. Transplantation 1984;38:293-8.

23. Pescovitz MD, Thistlethwiate JR Jr, Auchincloss H Jr, et al. Effect of class II antigen matching on renal allograft survival in miniature swine. J Exp Med 1984;160:1495-508.

24. Fabre JW. Rat kidney allograft model: was it all too good to be true. Transplantation 1982;34:223-4.

25. Sims FH. A comparison of the structural features of the walls 
of coronary arteries from ten different species. Pathology 1989;21:115-24.

26. Shi C, Russell ME, Bianchi C, Newell JB, Haber E. Murine model of acclerated transplant arteriosclerosis. Circ Res 1994;75:199-207.

27. Warren RP, Lofgreen JS, Steinmuller D. Factors responsible for the differential survival of heart and skin allografts in inbred rats. Transplantation 1973;16:458-65.

28. Clarke Forbes RD, Zheng S, Gomersall M, Al-Saffar M,
Guttmann RD. Evidence that recipient CD8 + T cell depletion does not alter development of chronic vascular rejection in a rat heart allograft model. Transplantation 1994;57:123846.

29. Stone CD, Rosengard BR, Hennein E, Mendeloff E, Sachs DH, Clark RE. Heterotopic heart transplantation in partially inbred miniature swine: the influence of $\mathrm{MHC}$ matching on rejection of cardiac allografts. Surg Forum $1990 ; 41: 417-23$

\section{1-800-55-MOSBY}

This number links you to the full text of articles published in over 25,000 journals, including all Mosby journals. MOSBY Document Express $^{(\mathbb{E}}$, a rapid response information retrieval service, provides quick turnaround, 24-hour availability, and speedy delivery methods. For inquiries and pricing information, call our toll-free, 24-hour order line: 1-800-55-MOSBY; outside the United States: 415-259-5046; fax: 415-259-5019; E-mail: mosbyexp@class.org. 